Micronutrient deficiencies in pregnant women with plasmodiasis

Akinbo et al. Afr. J. Clin. Exper. Microbiol. 2019; 20 (2): $127-136$

https://www.afrjcem.org

African Journal of Clinical and Experimental Microbiology ISSN 1595-689X

April 2019 Vol.20 No.2

AJCEM/1912: https://www.ajol.info/index.php/ajcem

Copyright AJCEM 2019. https://dx.doi.org/10.4314/ajcem.v20i2.6

4

Original Article

Open Access

\title{
Micronutrient deficiencies among pregnant women with Plasmodium falciparum infection in Owo, Ondo State, Nigeria
}

\author{
${ }^{1 *}$ Akinbo, F. O., ${ }^{1}$ Alabi, L. O., and ${ }^{2}$ Aiyeyemi, J. A. \\ ${ }^{1}$ Department of Medical Laboratory Science, School of Basic Medical Sciences, University of Benin, \\ Benin City, Edo State, Nigeria. \\ ${ }^{2}$ Department of Obstetrics and Gynaecology, Federal Medical Center, Owo, Ondo State, Nigeria \\ *Correspondence to: fgbengang@yahoo.com
}

\begin{abstract}
Background: Two important barriers to a successful pregnancy outcome are maternal under nutrition and malaria. This study was conducted to determine some micronutrient deficiencies among pregnant women infected with Plasmodium falciparum in Owo, Ondo State, Nigeria

Material and methods: Two hundred and fifty four participants aged 18 to 42 years consisting of 154 pregnant women attending antenatal clinic of the Federal Medical Center, Owo, and 100 apparently healthy non-pregnant women as controls were randomly enrolled in this study. Blood specimen was collected and analyzed for the detection of $P$. falciparum using $10 \%$ Giemsa staining technique while micronutrients (calcium, copper, iron and zinc) were analyzed using Atomic Absorption Spectrophotometer (AAS).

Results: Out of 154 pregnant women studied, 91 (59.1\%) had micronutrient deficiency (MND) while 5 out of $100(5.0 \%)$ non-pregnant control had micronutrient deficiency $(p<0.0001)$. Forty three $(27.9 \%)$ of the 154 pregnant women and $3(3.0 \%)$ of 100 non-pregnant control had $P$. falciparum infection $(p<0.0001)$. Forty three of the $91(47.3 \%)$ pregnant women and 3 of the $5(60 \%)$ nonpregnant women with MND had $P$. falciparum infection $(p=0.6681)$. All 43 pregnant women with MND but none of the 63 pregnant women without MND had $P$. falciparum infection $(p<0.0001)$. Similarly, all 3 non-pregnant women with $P$. falciparum infection had MND but none of the 95 nonpregnant women without MND had $P$. falciparum infection $(p<0.0001)$. Multiple micronutrient deficiencies of iron and calcium (65.3\%), iron and zinc (16.1\%) and iron and copper (18.6\%) were observed among pregnant women but none among non-pregnant women. Factors significantly associated with $P$. falciparum infection among pregnant women with MND were age group 23-27 years $(p=0.0109)$, first trimester gestational age $(p=0.0234)$, primiparity $(p=0.0303)$ and wet season $(p$ $<0.0173)$. There was no significant association between anaemia and prevalence of $P$. falciparum infection in pregnant women with MND $(p=0.1327)$ but pregnant women with iron deficiency were more likely to be infected with $P$. falciparum than those with other micronutrient deficiencies $(p=$ $0.0013)$

Conclusion: This study reported a higher prevalence rate of $27.9 \%$ for $P$. falciparum infection in pregnant women compared to $3 \%$ in non-pregnant women population, but a much higher rate of $47.3 \%$ among pregnant women with micronutrient deficiencies.
\end{abstract}

Key words: Micronutrient deficiencies, Plasmodium falciparum, pregnant women, Owo

Received January 4, 2019; Revised February 21, 2019; Accepted February 23, 2019

Copyright 2019 AJCEM Open Access. This article is licensed and distributed under the terms of the Creative Commons Attrition 4.0 International License (http://creativecommmons.org/licenses/by/4.0), which permits unrestricted use, distribution and reproduction in any medium, provided credit is given to the original author(s) and the source. 


\title{
Carences en micronutriments chez les femmes enceintes atteintes d'une infection à Plasmodium falciparum à Owo, dans I'État d'Ondo, au Nigéria
}

\author{
${ }^{1 *}$ Akinbo, F. O., ${ }^{1}$ Alabi, L. O., ${ }^{2}$ Aiyeyemi, J. A. \\ ${ }^{1}$ Département des sciences de laboratoire médical, École des sciences médicales de base, Université \\ du Bénin, Benin City, État d'Edo, Nigéria \\ ${ }^{2}$ Département d'obstétrique et de gynécologie, Centre médical fédéral, Owo, État d'Ondo, Nigéria \\ *Correspondance à: fgbengang@yahoo.com
}

\begin{abstract}
Abstrait
Contexte: La sous-nutrition maternelle et le paludisme sont deux obstacles importants à la réussite de la grossesse. Cette étude avait pour objectif de déterminer certaines carences en micronutriments chez les femmes enceintes infectées par Plasmodium falciparum à Owo, dans l'État d'Ondo, au Nigéria Matériel et méthodes: Deux cent cinquante-quatre participants âgés de 18 à 42 ans, dont 154 femmes enceintes fréquentant la clinique prénatale du Centre médical fédéral d'Owo et 100 femmes apparemment non enceintes et en bonne santé comme témoins ont été inscrits au hasard dans cette étude. Des échantillons de sang ont été prélevés et analysés pour la détection de $P$. falciparum en utilisant une technique de coloration à $10 \%$ de Giemsa, tandis que les micronutriments (calcium, cuivre, fer et zinc) ont été analysés à l'aide d'un spectrophotomètre d'absorption atomique (AAS) Résultats: Sur 154 femmes enceintes étudiées, $91(59,1 \%)$ avaient un déficit en micronutriments (MND), tandis que 5 sur $100(5,0 \%)$ des témoins non enceintes avaient un déficit en micronutriments $(p<0,0001)$. Quarante-trois $(27,9 \%)$ des 154 femmes enceintes et $3(3,0 \%)$ des 100 témoins non enceintes avaient une infection à $P$. falciparum $(p<0,0001)$. Quarante-trois des $91(47,3 \%)$ femmes enceintes et 3 des $5(60 \%)$ femmes non enceintes atteintes de MND avaient une infection à $P$. falciparum $(p=0,6681)$. Les 43 femmes enceintes atteintes de MND, mais aucune des 63 femmes enceintes sans MND n'a été infectée par $P$. falciparum $(p<0,0001)$. De même, les 3 femmes non enceintes atteintes de MND, mais aucune des 95 femmes non enceintes sans MND n'a été infectée par $P$. falciparum $(p<0,0001)$. Des carences multiples en micronutriments en fer et en calcium $(65,3 \%)$, en fer et en zinc $(16,1 \%)$ et en fer et en cuivre $(18,6 \%)$ ont été observées chez les femmes enceintes mais aucune chez les femmes non enceintes. Les facteurs significativement associés à l'infection à $P$. falciparum chez les femmes enceintes atteintes de MND étaient les groupes d'âge 23-27 ans ( $p=$ $0,0109)$, l'âge gestationnel au premier trimestre $(p=0,0234)$, primiparité $(p=0,0303)$ et saison des pluies $(p<0,0173)$. Il n'y avait pas d'association significative entre l'anémie et la prévalence de l'infection à P. falciparum chez les femmes enceintes atteintes de MND $(p=0,1327)$, mais les femmes enceintes présentant une carence en fer étaient plus susceptibles d'être infectées par $P$. falciparum que celles présentant d'autres carences en micronutriments $(p=0,0013)$

Conclusion: Cette étude a révélé un taux de prévalence plus élevé de $27,9 \%$ pour l'infection à $P$. falciparum chez les femmes enceintes, contre $3 \%$ chez les femmes non enceintes, mais un taux beaucoup plus élevé de $47,3 \%$ chez les femmes enceintes présentant des carences en micronutriments
\end{abstract}

Mots-clés: carences en micronutriments, Plasmodium falciparum, femmes enceintes, Owo

\section{Introduction:}

Malaria has been reported to be one of the three killer communicable diseases in Africa (1). An estimated 35,000 children in the Southern region of Nigeria die from malaria infection annually (2). Malaria is one of the main causes of maternal and child mortality with severe consequences on the population, social and economic development of countries ravaged by this disease $(3,4)$. It is estimated that each year over 125 million pregnant women living in low-and-middleincome countries are at risk of infection with $P$. falciparum and $P$. vivax (5). It has long been observed that populations residing in malaria endemic areas generally live under conditions that lead to poor nutritional status. Children and pregnant women are the worse hit by 
malaria and also affected by poor nutrition (6).

Pregnancy is a period in the life cycle of a woman when additional nutrients are needed to meet the metabolic and psychological demands as well as the increased requirements of the growing fetus and placenta (7). Many anatomic, biochemical and physiologic changes occur during pregnancy to maintain a healthy environment for the growing fetus (8). Maternal nutrition does not only impact the mother in terms of morbidity but also on the growth and development of the fetus (9). The quality of nutrition in the first 1000 days beginning from the mother's pregnancy through her child's second birthday is a critical window when a child's brain and body develop rapidly and good nutrition is essential to lay the foundation for a healthy and productive future (10). Under nutrition is an underlying cause of death and it leaves millions more with lifelong physical and mental impairments (11). Poor quality diet due to inadequate intake of animal source foods particularly in developing countries has been implicated as the major cause of micronutrient deficiencies. In addition, women who avoid meat and/or milk in developed countries have been reported to have higher risk of micronutrient depletion during pregnancy and lactation (12). Several micronutrient deficiencies have been established to contribute to abnormal prenatal development and/or pregnancy outcome (12). The common micronutrients are vitamins $A, B, C, D$ and $\mathrm{E}$, calcium, zinc, copper, iron, and magnesium $(4,13)$.

Deficiencies in maternal micro nutrient status may be a product of poor quality diets, high fertility rates, repeated pregnancies, short inter pregnancy intervals and increased physiological needs. All of these factors may be aggravated by inadequate healthcare systems with poor capacity, poverty and inequities, and socio-cultural factors such as early marriage, adolescent pregnancies and traditional dietary practices $(14,15$, $16,17,18)$. The two important barriers to a successful pregnancy outcome are maternal undernutrition which contributes an estimated 800,000 neonatal mortality annually and malaria, estimated to cause about 900,000 low birth weight deliveries and over 100,000 infant deaths yearly $(19,20,21)$. Foetal exposure to under nutrition is associated with congenital anomalies, intrauterine growth restriction, low birth weight, stunting in childhood, shorter adult height, lower educational attainment, and reduced economic activity (22).

Adequate intakes of micronutrients are needed for the development of efficient immune system (23). There is a growing body of reports linking micronutrient deficiencies and malaria caused by $P$. falciparum in developing countries where certain micronutrient deficiencies may be predisposing factors $(24,25,26,27)$. There is paucity of data on micronutrient deficiencies among pregnant women with $P$. falciparum infection in Owo, Ondo State. Against this background, this study was conducted to determine the micronutrient deficiencies among $P$. falciparum infected pregnant women in Owo, Ondo State.

\section{Materials and methods:}

\section{Study area}

This study was carried out at the Federal Medical Center, Owo, Ondo State. The hospital is a tertiary health institution with a referral status to Primary Health Care Centers, Maternity and Antenatal Clinics around Owo town.

\section{Study population}

This study was conducted between January and June, 2018 at the Federal Medical Center, Owo, Ondo State. Two hundred and fifty four participants consisting of 154 pregnant women attending antenatal clinics at the Federal Medical Center, and 100 apparently healthy, age matched non pregnant women as controls were enrolled in this study by simple random sampling technique. The participants' age ranged from $18-42$ years.

Participants who refused informed 
consent, pregnant women on treatment plan for trace elements (supplements) and those on antimalarial agents were excluded from the study. A well structured questionnaire was administered to collect demographic information from participants whereas informed consent was sought from participants before specimen collection. Information obtained through the questionnaire includes age, marital status, gestational age and parity amongst others. The Ethics and Research Committee of the Federal Medical Center, Owo, Ondo State approved the protocol for this study.

\section{Collection of blood specimen}

About $10 \mathrm{ml}$ of venous blood was collected from each participant, $5 \mathrm{ml}$ of which was dispensed into ethylene diamine tetra acetic acid (EDTA) container and properly mixed. The remaining $5 \mathrm{ml}$ was dispensed into a plain tube and allowed to clot for the serum to separate.

\section{Processing of specimen}

Thick and thin blood films from each blood specimen were made, allowed to air-dry and stained in $10 \%$ Giemsa stain solution for $30 \mathrm{~min}$. The stained smears were rinsed in buffer solution and allowed to air-dry. The stained thick films were examined under bright field light microscope for estimation of malaria parasite density while the thin films were examined for species of Plasmodium. A total of 200 fields per film were examined (28).

Haemoglobin concentration was determined using the automated analyzerSysmex Kx-21 (Sysmex Cooperation,
Kobe, Japan). According to the WHO cutoff, anaemia was determined as haemoglobin concentration less than 11 $\mathrm{g} / \mathrm{dl}$ for pregnant women and less than 12 $\mathrm{g} / \mathrm{dl}$ for non-pregnant women $(29,30)$.

The micronutrients assayed for were calcium, copper, iron and zinc using Atomic Absorption Spectrophotometer (Buck Scientific 210 VGP, East Norwalk, CT). Briefly, for each element, the AAS was auto-zeroed using the flame from the lowest to the highest calibration. The corresponding absorbance was obtained and the graph of absorbance against concentration of the trace elements present being displayed in parts per million ( $\mathrm{ppm})$ (31).

\section{Statistical analysis}

The frequency data were analyzed by Chi-square test while the potential risk factors were analyzed using odd ratios. The statistical software used in the data analyses was INSTAT $^{\circledR}$ (GraphPad Software Inc, La Jolla, CA, USA).

\section{Results:}

The micronutrients assayed in this study were calcium, copper, iron and zinc. Out of 154 pregnant women studied, 91 $(59.1 \%)$ had micronutrient (iron) deficiency while 5 out of 100 (5.0\%) nonpregnant control had micronutrient (iron) deficiency (OR 27.44, $p<0.0001$ ). This trend was similar for copper, calcium and zinc (Table 1) which showed that pregnancy status was significantly associated with reduction in all micronutrients assayed with iron having the greatest reduction.

Table 1: Micronutrient deficiency status of pregnant and non-pregnant women population

\begin{tabular}{ccccccc}
\hline $\begin{array}{c}\text { MND } \\
\text { status }\end{array}$ & $\begin{array}{c}\text { Pregnant }(\%) \\
\mathrm{n}=154\end{array}$ & $\begin{array}{c}\text { Non-pregnant }(\%) \\
\mathrm{n}=100\end{array}$ & $\begin{array}{c}\text { Total }(\%) \\
\mathrm{n}=254\end{array}$ & OR & $95 \%$ CI & $P$ value \\
\hline Iron & $91(59.1)$ & $5(5)$ & $96(37.8)$ & 27.44 & $10.559-71.332$ & $<0.0001$ \\
Copper & $38(24.7)$ & $2(2)$ & $40(15.7)$ & 16.052 & $3.775-68.052$ & $<0.0001$ \\
Zinc & $29(18.8)$ & $0(0)$ & $29(11.4)$ & 47.247 & $2.850-783.34$ & $<0.0001$ \\
Calcium & $24(15.6)$ & $1(1)$ & $25(9.8)$ & 18.277 & $2.430-137.49$ & $<0.0001$ \\
\hline
\end{tabular}

MND = Micronutrient Deficiency 
Table 2: Risk factors associated with MND and P. falciparum infection among studied population

\begin{tabular}{|c|c|c|c|c|c|}
\hline Risk factors & $\begin{array}{l}\text { No of pregnant } \\
\text { women with } \\
\text { MND (\%) }\end{array}$ & $\begin{array}{l}\text { No infected } \\
\text { with } P \text {. } \\
\text { falciparum (\%) }\end{array}$ & OR & $95 \% \mathrm{CI}$ & $P$ value \\
\hline \multicolumn{6}{|l|}{ 1. Age group } \\
\hline $18-22$ & 26 & $9(32.1)$ & & & 0.0109 \\
\hline $23-27$ & 25 & $18(72.0)$ & & & \\
\hline $28-32$ & 15 & $8(53.3)$ & & & \\
\hline $33-37$ & 20 & $6(30.0)$ & & & \\
\hline $38-42$ & 5 & $2(40.0)$ & & & \\
\hline \multicolumn{6}{|l|}{ 2. Marital status } \\
\hline Single & 19 & $7(36.8)$ & & & 0.5933 \\
\hline Married & 62 & $31(50.0)$ & & & \\
\hline Widowed & 10 & $5(50.0)$ & & & \\
\hline \multicolumn{6}{|c|}{ 3. Gestational age } \\
\hline $1^{\text {st }}$ trimester & 28 & $19(67.9)$ & & & 0.0234 \\
\hline $2^{\text {nd }}$ trimester & 38 & $16(42.1)$ & & & \\
\hline $3^{\text {rd }}$ trimester & 25 & $8(32.01)$ & & & \\
\hline \multicolumn{6}{|l|}{ 4. Parity } \\
\hline Primiparous & 35 & $22(62.9)$ & 2.821 & $1.177-6.757$ & 0.0303 \\
\hline Multiparous & 56 & $21(37.5)$ & & & \\
\hline \multicolumn{6}{|c|}{ 5. Seasonal variation } \\
\hline Dry season & 33 & $10(30.3)$ & 0.3294 & $0.1331-0.8185$ & 0.0173 \\
\hline Wet season & 58 & $33(56.9)$ & & & \\
\hline \multicolumn{6}{|c|}{ 6. Pregnancy status in relation to MND and $P$. falciparum infection } \\
\hline $\begin{array}{l}\text { Pregnancy } \\
\text { status }\end{array}$ & $\begin{array}{l}\text { No of women } \\
\text { with MND }\end{array}$ & $\begin{array}{l}\text { No infected } \\
\text { with } P \text {. } \\
\text { falciparum }\end{array}$ & OR & $95 \% \mathrm{CI}$ & $P$ value \\
\hline Pregnant & 91 & $43(47.3)$ & 0.5972 & $0.09519-3.747$ & 0.6681 \\
\hline Not pregnant & 5 & $3(60.0)$ & & & \\
\hline
\end{tabular}

Forty three $(27.9 \%)$ of the 154 pregnant women and $3(3.0 \%)$ of 100 non-pregnant control had $P$. falciparum infection (OR 12.526, $p<0.0001$ ) indicating that pregnancy is a significant risk factor for acquisition of $P$. falciparum infection (Table 2). Forty three of the 91 $(47.3 \%)$ pregnant women and 3 of the 5 $(60 \%)$ non-pregnant women with MND had $P$. falciparum infection, indicating that MND is an independent risk factor for $P$. falciparum infection in both pregnant and non-pregnant subjects (OR 0.5972, $p=$ 0.6681) (Table 2).

MND as a significant risk factor for $P$. falciparum infection among the studied population is further highlighted by the fact that all 43 pregnant women with MND but none of the 63 pregnant women without MND had $P$. falciparum infection (OR 113.9110, $p<0.0001$ ). Similarly, all
3 non-pregnant women with $P$. falciparum infection had MND but none of the 95 non-pregnant women without MND had $P$. falciparum infection (OR 267.40, $p<$ 0.0001) (Table 3).

Table 3: MND and $P$. falciparum infections in pregnant and non-pregnant women population

(a)

\begin{tabular}{lccccc}
\hline MND status & $\begin{array}{c}\text { No with } \\
\text { pregnancy }\end{array}$ & $\begin{array}{c}\text { No with } P . \\
\text { falciparum } \\
\text { infection }\end{array}$ & OR & $95 \% \mathrm{CI}$ & P value \\
\hline MND positive & 91 & 43 & 113.9110 & $6.835-1898.3$ & $<0.0001$ \\
MND negative & 63 & 0 & & & \\
\hline \multicolumn{6}{c}{ (b) } \\
\hline MND status & No without & No with P. & OR & $95 \%$ CI & P value \\
& pregnancy & falciparum \\
infection & & & \\
\hline MND positive & 3 & 2 & 267.40 & $10.694-6686.3$ & $<0.0001$ \\
MND negative & 0 & 95 & & & \\
\hline MND = Micronutrient Deficiency & &
\end{tabular}


Multiple micronutrient deficiencies of iron and calcium (65.3\%), iron and zinc $(16.1 \%)$ and iron and copper (18.6\%) were observed among pregnant women (Table 4) but no multiple micronutrient deficiency was observed among nonpregnant women.

Table 4: Micronutrient deficiency combinations in pregnant women

\begin{tabular}{cc}
\hline Micronutrient deficiency & Frequency \\
\hline Iron + calcium & $77(65.3)$ \\
Iron + zinc & $19(16.1)$ \\
Iron + copper & $22(18.6)$ \\
Total & 118 \\
\hline
\end{tabular}

Age significantly affected the prevalence of $P$. falciparum infection among pregnant women with $\operatorname{MND}(p=$ 0.0109 ) with the 23-27 years age group having the highest prevalence $(46.2 \%)$. Marital status did not affect the prevalence of $P$. falciparum infection among pregnant women with $\operatorname{MND}(p=$ 0.5933). Gestational age affected significantly the prevalence of $P$. falciparum infection in pregnant women with MND ( $p=0.0234)$ with those in the $1^{\text {st }}$ trimester having the highest prevalence of $P$. falciparum infection $(67.9 \%)$. Primiparous women with MND were significantly more proned to $P$. falciparum infection $(p=0.0303)$, with a 1 to 6 -fold risk of acquisition.

The prevalence of $P$. falciparum infection among pregnant women with MND was higher in rainy season $(56.9 \%)$ than in dry season $(30.3 \%)(p<0.0173)$ (Table 2). There was no significant association between anaemia and prevalence of $P$. falciparum infection in pregnant women with MND $(p=0.1327)$ (Table 5). The three cases of $P$. falciparum infection in non-pregnant women with MND were also seen in those without anaemia. Pregnant women with iron deficiency are more likely to be infected with $P$. falciparum than those with other micronutrient deficiencies $(p=0.0013)$ (Table 6).

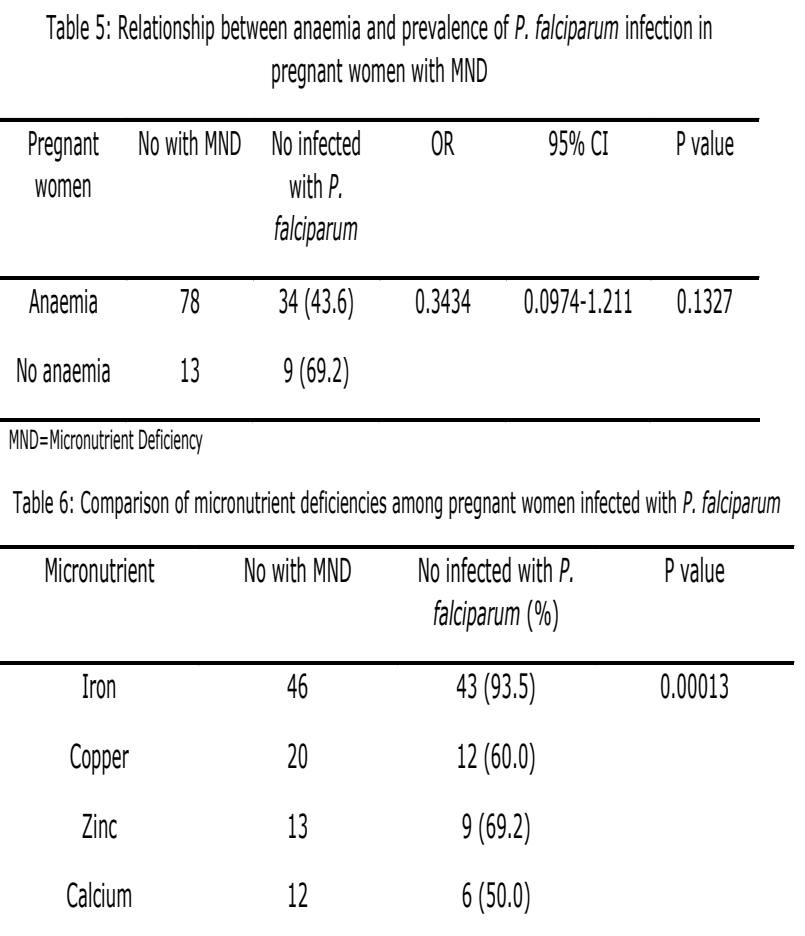

MND=Micronutrient deficiency

\section{Discussion:}

Pregnant women are often deficient in several nutrients particularly micronutrients, which can negatively impact on their well being as well as the health, growth and development of their fetus and infants (32). Micronutrient deficiencies in pregnancy have been associated with adverse health outcomes such as maternal anaemia, maternal and perinatal mortality, low birth weight, preterm birth, intra-uterine growth retardation, altered immune response and cognitive deficits in the newborn $(20,33-$ 37). Malaria has been associated with malnutrition and micronutrient deficiencies and certain micronutrient deficiencies may predispose to malaria especially among pregnant women (4). To the best of our knowledge, this is the first study to assess some micronutrient deficiencies among pregnant women with $P$. falciparum infection in Owo, Ondo State of Nigeria.

An overall prevalence of $27.9 \%$ for $P$. falciparum infection was observed among pregnant women population 
studied but $47.3 \%$ among pregnant women with MND. The prevalence of $27.9 \%$ in this study is similar to $24 \%$ rate reported in Ouagadougou, Burkina Faso among pregnant women and $26.7 \%$ reported in Yaqshid district, Somalia also among pregnant women (38, 39). Pregnancy has been reported to reduce immunity as a result of general immunosuppression sustained by elevated level of serum cortisol which allows fetal allograft retention but renders the women susceptible to various infectious diseases (40). This may partly explain the reason for the high prevalence of $P$. falciparum in pregnancy in our study compared to the low rate of $3 \%$ among non-pregnant age matched control.

In this study, pregnancy was a significant risk factor for micronutrients deficiency for all the micronutrients assayed ( $p<0.0001$ ), with a 10 to 71fold increased risk for pregnant women to be micronutrient deficient. Requirement for some micronutrients such as calcium, copper, iron and zinc are known to increase during pregnancy due to greater needs of the mother to increase her body tissue reserves, and to meet the high metabolic demands and development of the placenta and fetus $(41,42)$.

Micronutrients play an important role during pregnancy and reduction may cause physical abnormalities and diseases which increase the risk of adverse pregnancy outcomes (43). The levels of the four micronutrients assayed in our study were significantly reduced among the pregnant women, with highest reduction in the level of iron. Iron deficiency in pregnancy may cause anaemia which can lead to chronic fetal hypoxia, premature birth and perinatal mortality (44, 45). Pregnant women should therefore be encouraged particularly to consume iron-rich diet in order to forestall these adverse pregnancy outcomes.

There were cases of multiple micronutrient deficiencies observed among pregnant women in this study. In addition, pregnancy caused more reduction of the combination of iron and calcium levels (50\%) when compared with other micronutrient combinations. Individually, deficiencies of any of these micronutrients have been associated with adverse outcomes such as preterm delivery, miscarriage, premature rupture of membranes, foetal nervous system damage, gestational hypertension, worsening of post-partum haemorrhage, maternal and fetal ossification disorders, and anomalies in DNA replication and transcription (46, 47, 48, 49, 50). Multiple micronutrients deficiency is expectedly associated with severe complications in pregnancy, childbirth and fetal development (51, 52). Adequate micronutrient supplementation in pregnancy is advocated to break the vicious circle that undernutrition can engender from pregnancy to the newborn through childhood, adolescence, and pregnancy in the next generation (53).

In this study, age was significantly associated with prevalence of $P$. falciparum infection among pregnant women with MND ( $p=0.0109)$ with those in the 23-27 years age group having the highest prevalence $(72.0 \%)$. The nutritional status of Nigerians has over the last few years been poor particularly with recent economic recession in the country. The National Demographic Health Survey 2013 reports indicated that nutritional status among Nigerian women aged 15-49 years has only minimally improved over a 10 year period, with prevalence of undernutrition of $15 \%$ in 2003 reduced to $11 \%$ in 2013 (54). This may partly explain our findings in this age group. Marital status was not associated with the prevalence of $P$. falciparum infection among pregnant women with $\operatorname{MND}(p=$ 0.5933) though the three cases of $P$. falciparum infection in the non-pregnant women were observed only in married subjects.

It has been reported that malaria in early pregnancy increase the risk of adverse pregnancy outcomes after organogenesis and placentation (55). In this study, pregnant women with MND in the first trimester had the highest prevalence of malaria $(67.9 \%)$ when 
compared to other trimesters which imply that majority of the women in our study are at high risk of adverse pregnancy outcome.

Our study revealed that primiparous women with MND had a higher risk (1 to 6-fold increased risk) of acquiring $P$. falciparum infection than multiparous women. This observation may be ascribed to inexperience in the act of pregnancy coupled with the fact that primiparous women have the propensity for not attending antenatal clinic early enough during the period they should have received health talks bothering on nutrition and health status during pregnancy.

$\begin{array}{rrrr}P . & \text { falciparum infection among } \\ \text { pregnant } & \text { women } & \text { occurred more }\end{array}$ frequently in rainy season with high prevalence rate of $46.6 \%$ compared to $16.7 \%$ during the dry season. Rainy season provides ecological alterations favouring the breeding of the mosquito vector which enhance transmission of malaria. Other possible factors for this include inadequate waste disposal facilities, poor drainage system and poor standards of living (56).

Contrary to the World Health Organization (WHO) report that 25\% of the world population has anaemia with highest prevalence among preschool children and pregnant women (57), quite surprisingly, we did not find any association between anaemia and prevalence of $P$. falciparum in pregnant women with MND in our study ( $p=$ $0.1327)$. Also, the three non-pregnant women with MND who had $P$. falciparum infection did not have anaemia. The reason for this finding is not clear.

Iron deficiency and malaria have reportedly been described as significant co morbidities in most developing countries, and both maladies disproportionately affect pregnant women and children (58). In our study, pregnant women with iron deficiency were more likely to be infected with $P$. falciparum than those with other micronutrient deficiencies $(p=0.0013)$. Iron is essential for the survival of malaria parasite as an essential cofactor for the
DNA replication enzyme, ribonucleotide reductase, required to fuel the rapid intraerythrocytic proliferation of the parasite (59) and for pyrimidine and heme biosynthesis (60). This may explain the synergy of iron deficiency in pregnancy and $P$. falciparum infection in our study.

\section{Conclusion:}

Our study reported a higher prevalence rate of $27.9 \%$ for $P$. falciparum infection in pregnant women compared to $3 \%$ in non-pregnant women population, and a much higher rate of $47.3 \%$ among pregnant women with micronutrient deficiencies. Emphasis on health education, adequate intake of well balanced diets consisting of the appropriate micronutrients in the right proportion and intake of nutritional supplements are advocated in pregnancy.

\section{Acknowledgements:}

We thank the Management of Federal Medical Center, Owo, Ondo State for providing specimens used in this study. We equally appreciate all the participants who consented to participate in this study.

\section{References:}

1. Greenwood, B., and Mutabingwa, T. Introduction to Malaria in 2002. Nature. 2002; 415: 670-672

2. Adedapo, A. A., Falade, C. O., Kotila, R. T., and Ademowo, O. G. Age as a risk factor thrombocytopenia and anaemia in children treated for acute uncomplicated falciparum malaria. J Vector Borne Dis. 2007; 44: 266271.

3. Kwiatkowski, D. P. How malaria has affected the human genome and what human genetics can teach us about malaria. Am J Hum Genet. 2005; 77: 171-190

4. Nwachukwu, N. F., Mishra, M., Marcelle, T., and Owolabi, J. B. Effects of Vitamins in Augmentation of Malaria Treatment: A review. Asian Pac J Health Sci. 2016; 3(4):34-43.

5. Dellicour, S., Tatem, A. J., Guerra, C. A., et al. Quantifying the number of pregnancies at risk of Malaria in 2007: a demographic study. PLoS Med. 2010; 7: e1000221.

6. Shankar, A. H. Nutritional Modulation of Malaria Morbidity and Mortality. J. Infect. Dis. $2000 ; 182(1)$ : 37-53. 
7. Broughton, F. P. Maternal physiology, in Dewhurst's Textbook of Obstetrics and Gynaecology, D. K. Edmonds, Ed., Blackwell Publishing, Oxford, UK 2007: 732

8. Turner, E. R. Nutrition during pregnancy. Modern Nutrition in Health and Disease, 10th edn. 2006: 2069

9. Barker, D. J. P. Mothers, babies and health in later life. 2nd edn. Edinburgh: Churchill Livingstone; 1998: 217

10. State of the World's Mothers: Nutrition in the First 1,000 Days. May 2012.

11. Paul, V. K., Sachdev, H. S., Mavalankar, D., et al. Reproductive health, and child health and nutrition in India: meeting the challenge. Lancet. 2011; 377(9762): 332349.

12. Allen, L. H. Biological mechanisms that might underlie iron's effects on fetal growth and preterm birth. Am. J. Clin. Nutr. 2005; 81: 1206-2012

13. da Silva Lopes, K., Ota, E., Shakya, P., et al. Effects of nutrition interventions during pregnancy on low birth weight: an overview of systematic reviews. BMJ Glob Health. 2017; 2: 1-11

14. Darnton-Hill, I., Webb, P., Harvey, P. W. J., et al. Micronutrient deficiencies and gender: Social and economic costs. Am J Clin Nutr. 2005, 819: 1198-1205

15. Shrimpton, R., Huffman, S. L., Zehner, E. R., et al. Multiple micronutrient supplementation during pregnancy in developing country settings: Policy and program implications of the results of a meta-analysis. Food Nutr Bull. 2009, 30: 556-573

16. Torheim, L. E., Ferguson, E. L., Penrose, K., et al. Women in resource-poor settings are at risk of inadequate intakes of multiple micronutrients. J Nutr 2010; 140: 20512058

17. Matthews, Z., Channon, A., Neal, S., et al. Examining the "urban advantage" in maternal health care in developing countries. PLoS Med. 2010; 7: e1000327, doi:10.1371/journal.pmed.1000327

18. Darnton-Hill, I. Global burden and significance of multiple micronutrient deficiencies in pregnancy. In: Bhutta, Z. A., Hurrell, R. F., and Rosenberg, I. H. (edn). Meeting Micronutrient Requirements for Health and Development; Nestlé Nutrition Institute Workshop Series Karger: Basel, Switzerland, 2012; 70: 49-60

19. Desai, M, ter Kuile, F. O., Nosten, F., et al. Epidemiology and burden of malaria in pregnancy. Lancet Infect Dis. 2007; 7: 93104

20. Black, R. E., Victoria, C. G., Walker, S. P., et al. Maternal and child undernutrition and overweight in low-income and middle income countries. Lancet. 2013; 382 (9890): 427-451

21. Walker, P. G., ter Kuile, F. O., Garske, T., et al. Estimated risk of placental infection and low birth weight attributable to Plasmodium falciparum malaria in Africa in 2010: a modelling study. Lancet Glob Health. 2014; 2(8): 460-467

22. Victoria C. G., Adair, L., Fall, C., et al. Maternal and child undernutrition: Consequences for adult health and human capital. Lancet. 2008; 371: 340-357

23. Maggini, S., Wintergerst, E. S., Beveridge, S., et al. Selected vitamins and trace elements support immune function by strengthening epithelial barriers and cellular and humoral immune responses. $\mathrm{Br} \mathrm{J}$ Nutr. 2007; 98 (1): 29-35

24. Galan, P., Samba, C., Luzeau, N., et al. Vitamin A deficiency in pre-school age Congolese children during malarial attacks. Part 2: Impact of parasitic disease on vitamin A status. Intern J Vitamin and Nutr Res. 1990; 60: 224-228

25. Tabone, M. D., Muanza, K., Lyagoubi, M., et al. The role of interleukin-6 in vitamin A deficiency during Plasmodium falciparum malaria and possible consequences for vitamin $A$ supplementation. Immunology. 1992; 75: 553-554

26. Shankar, A. H., and Prasad, A. S. Zinc and immune function: The biological basis of altered resistance to infection. Am J Clin Nutr. 1998; 68:447-463

27. Nyakeriga, A. M., Troye-Blomberg, M., Chemtai, A. K., et al. Malaria and nutritional status in children living on the coast of Kenya. Am J Clin Nutr. 2004; 80: 16041610.

28. Cheesbrough, M. District laboratory practice in tropical countries: examination of faecal specimens. Cambridge: Cambridge University Press; 2005: 96-110.

29. Blanc, B., Finch, C. A., and Hallberg, L. Nutritional anaemias. Report of a WHO Scientific Group. WHO Tech Rep Ser. 1968; 405: $1-40$

30. Beutler, E., and Waalen, J. The definition of anaemia: what is the lower limit of normal of the blood haemoglobin concentration? Blood. 2006; 107: 1747-1750

31. Greenberg, J. P., Zimmerman, P. R., Chatfield, R. B.. Hydrocarbons and carbon monoxide in African savannah air. Geophysical Research Letters. 1985; 12: doi: $10.1029 / G L 012 \mathrm{i} 003 p 00113$.

32. Ramakrishnan, U., and Huffman, S. L. Multiple micronutrient malnutrition: What can be done? In: Semba, R., and Bloem, M. (eds). Nutrition and health in developing countries, 2nd ed. Totowa, NJ, USA: Humana Press, 2008.

33. Mori, R., Ota, E., Middleton, P., et al. Zinc supplementation for improving pregnancy and infant outcome. Cochrane Database Syst Rev. 2012; 2: CD000230

34. Stevens, G. A., Finucane, M. M., De-Regil, L. M., et al. Global, regional, and national trends in haemoglobin concentration and prevalence of total and severe anaemia in 
children and pregnant and non-pregnant women for 1995-2011: A systematic analysis of population-representative data. Lancet Glob Health 2013; 1: 16-25.

35. Burke, R. M., Leon, J. S., and Suchdev, P. S. Identification, prevention and treatment of iron deficiency during the first 1000 days. Nutrients. 2014; 6: 4093-4114.

36. Pena-Rosas, J. P., De-Regil, L. M., GarciaCasal, M. N., et al. Daily oral iron supplementation during pregnancy. Cochrane Database Syst Rev. 2015: 12: CD004736

37. Gernand, A. D., Schulze, K. J., Stewart, C. $P$., et al. Micronutrient deficiencies in pregnancy worldwide: Health effects and prevention. Nat Rev Endocrinol. 2016; 12: 274-289

38. Douamba, F. Z., Bisseye, C., Djigma, F. W., et al. Asymptomatic Malaria Correlates with Anaemia in Pregnant Women at Ouagadougou, Burkina Faso. J Biomed Biotech. 2012; doi:10.1155/2012/198317

39. Muhammad, F., Yarow, A. M., Hossain, M. A., et al. Prevalence of Plasmodium falciparum among pregnant women in Yaqshid District of Somalia. Daffodil Intern University J Allied Health Sci. 2016; 3(1\&2): 61-68.

40. Meeusen, E. N., Bischof, R. J., Lee, C. S. Comparative T-cells response during pregnancy in large animals and humans. Am J Repr Immunol. 2001; 46: 169-179

41. Ladipo, O. A. Nutrition in pregnancy. Mineral and vitamin supplements. Am J Clin Nutr. 2000; 72: 280-290

42. Black, R. E. Micronutrients in Pregnancy. $\mathrm{Br}$ J Nutr. 2001; 85: 193-197

43. Sakamoto, M., Yasutake, A., Domingo, J. L., et al. Relationships between trace element concentrations in chronic tissue of placenta and umbilical cord tissue: potential use as indicators for prenatal exposure. Environ Int. 2013; 60: 106-111

44. Narasinga, R. B. S. Anaemia and micronutrient deficiency. Natl Med J India. 2003; 16(2): 46-50.

45. Pathak, P., Kapil, U., Kapoor, S. K., et al.. Prevalence of multiple micronutrient deficiencies amongst pregnant women in a rural area of Haryana. Indian J Pediatr. 2004; 71:1007-1114

46. Ergaz, Z., Shoshani-dror, D., Guillemin, C. et al. The effect of copper deficiency on fetal growth and liver anti-oxidant capacity in the Cohen diabetic rat model. Toxicol. Appl. Pharmacol. 2012; 265: 209-220

47. Shen, P-J., Gong, B., Xu, F-Y., and Luo, Y. Four trace elements in pregnant women and their relationships with adverse pregnancy outcomes. European Rev Med Pharmacol. Sci. 2015; 19: 4690-4697

48. Esteban-Vasallo, M. D., Aragonés, N., Pollan, M., Lópezabente, G., and PerezGomez B. Mercury, cadmium, and lead levels in human placenta: a systematic review. Environ Health Perspect. 2012; 120: 1369- 1377

49. Taylor, C. M., Golding, J., and Emond, A. M. Lead, cadmium and mercury levels in pregnancy: the need for international consensus on levels of concern. J Dev Orig Health Dis. 2014; 5: 16-30

50. Dickinson, N., Rankin, J., Pollard M., et al. Evaluating environmental and social influences on iron and zinc status of pregnant subsistence farmers in two geographically contrasting regions of southern Malawi. Sci Total Environ. 2014; 500-501: 199-210

51. Berti, C., Biesalski, H. K., Gärtner, R., et al. Micronutrients in pregnancy: Current knowledge and unresolved questions. Clin Nutr. 2011; 30: 689-701

52. Bhutta, Z. A., Das, J. K., Rizvi, A., et al. Lancet Nutrition Interventions Review Group; the Maternal and Child Nutrition Study Group. Evidence-based interventions for improvement of maternal and child nutrition: What can be done and at what cost? Lancet. 2013: 382: 452-477

53. Adinma, J., Umeononihu, O. S., and Umeh, M. N. Maternal nutrition in Nigeria. Trop J Obstetr Gynaecol. 2017; 34:79-84

54. National Population Commission (NPC) [Nigeria] and ICF International. 2014. Nigeria Demographic and Health Survey 2013. Abuja, Nigeria, and Rockville, Maryland, USA: NPC and ICF International

55. Huynh, B. T., Cottrell, G., Cot, M., and Briand $V$. Burden of malaria in early pregnancy: a neglected problem? Clin. Infect Dis. 2014; 60(4): 598-604

56. Erhabor, O., Mohammad, H. J., Ahmed, $\mathrm{H}$. M., et al. Effect of Plasmodium Parasitaemia on some Haematological Parameters in Children Living in Sokoto, North Western, Nigeria. Intern J Clin Med Res. 2014; 1(2): 57- 64.

57. de Benoist, B., McLean, E., Egli, I., and Cogswell M. (eds). Worldwide prevalence of anaemia 1993-2005. WHO Global Database on Anaemia Geneva. World Health Organization. 2008

58. Okebe, J. U., Yahav, D., Shbita, R., et al. Oral iron supplements for children in malaria-endemic areas. Cochrane Database Syst Rev. doi: 10.1002/14651858

59. Rubin, H., Salem, J. S., Li, L. S., et al. Cloning, sequence determination and regulation of the ribonucleotide reductase subunits from Plasmodium falciparum: a target for antimalarial therapy. Proc Natl Acad Sci. 1993; 90: 9280-9284

60. Nagaraj, V. A., Sundaram, B., Varadarajan, N. M., et al. Malaria parasite-synthesized heme is essential in the mosquito and liver stages and complements host heme in the blood stages of infection. PLoS Pathol. 2013; 9:e1003522 